\title{
Simulation of Liquid Film Spreading on Tip of Spray Injector
}

\author{
Eiji Ishii*, Kazuki Yoshimura, Tomoyuki Hosaka \\ Center for Technology Innovation, Research \& Development Group, Hitachi, Ltd., Hitachi, Japan \\ Email address: \\ eiji.ishii.qm@hitachi.com (E. Ishii), kazuki.yoshimura.ox@hitachi.com (K. Yoshimura), tomoyuki.hosaka.ra@hitachi.com (T. Hosaka) \\ ${ }^{*}$ Corresponding author
}

To cite this article:

Eiji Ishii, Kazuki Yoshimura, Tomoyuki Hosaka. Simulation of Liquid Film Spreading on Tip of Spray Injector. International Journal of Energy and Power Engineering. Vol. 10, No. 2, 2021, pp. 30-36. doi: 10.11648/j.ijepe.20211002.11

Received: March 9, 2021; Accepted: March 25, 2021; Published: April 1, 2021

\begin{abstract}
The behaviors of fuel films adhering to the tip of a fuel injector for automotive gasoline direct-injection engines was simulated by the computational fluid dynamics. Liquid film adhering to the tip of the fuel injector is a source of carbon deposits; the film spreads on the surfaces of the tip and remains there under certain wetting conditions. The deposit build-up can clog the injector nozzles, which can alter the spray pattern, furthermore, deposits on the tips of injectors are a source of particulate matter (PM) discharged from the engine. In order to prevent air pollution, it is essential to develop a technology to reduce PM. The spread of fuel adhering to the tip of a fuel injector was simulated using the moving particle semi-implicit method, and a previously developed particle/grid hybrid method was used to study the effects of spray plumes. The simulated distribution of the film qualitatively agreed with the measured distribution of carbon deposits. Fuel film formed on the concave and convex wall surfaces. The fuel film and carbon deposits were unevenly distributed in the air flow direction. Investigation of the behaviors of floating droplets around the tip between fuel injections revealed that the droplets were pulled toward the tip wall due to a reverse air flow generated by the fuel plumes ejected by the injector nozzles. These droplets then merged as a part of the fuel film, which spread toward the injection nozzles due to the air flow directed at the nozzles. Some of the film was sucked into the spray plumes and then re-injected into the air region again. The simulated fuel film behaviors on the tip qualitatively agreed with the measured ones. Furthermore, the simulation showed that optimizing the surface shape of the fuel injector tip, particularly the concave portion, is important for reducing particulate matter.
\end{abstract}

Keywords: Fuel Spray, Fuel Injector, Computational Fluid Dynamics, Particulate Matter, Tip Wetting

\section{Introduction}

Liquid film adhering to the tip of a spray injector is a source of carbon deposits; the film spreads on the surfaces of the tip and remains there under certain wetting conditions. Deposit build-up can clog the injector nozzles, which can alter the spray pattern. We investigated the behaviors of liquid film adhering to the tip of a spray injector, particularly that of a film on the tip of a fuel injector for automotive gasoline direct-injection (GDI) engines.

Deposits on the tips of automotive engine fuel injectors are a source of particulate matter (PM) discharged from the engine. This PM has become a major contributor to air pollution. Fuel that adheres to low-temperature walls generates carbon deposits. Fuel soaking into these deposits generates PM due to combustion at low temperature. With GDI engines, fuel is directly injected into the combustion chamber by a fuel injector, so fuel adhesion on the walls is more likely to occur than with port-fuel-injection engines. Huang et al. [1] investigated nozzle tip wetting in a GDI injector and its link with nozzle internal flow. Collision of the spray plume with the inner-wall surfaces at the nozzle outlets forms fuel films around the nozzles, which is one source of tip wetting. The tip wetting increases when flash boiling occurs within the nozzle flow. Khan et al. [2] developed a spray-injection simulation model that captures the rapid expansion of plumes in the region near the nozzles, and Senda et al. [3] modeled the atomization process. Araneo and Dondé [4] analyzed the effects of fuel temperature and chamber pressure on the spray, with a focus on the behavior of the global spray angles both near and far from the injector. Nouri et al. [5] used a transparent enlarged model to investigate the internal flow cavitation in a multi-nozzle injector for GDI engines. Sou et al. [6] used synchrotron x-ray phase-contrast imaging to study cavitation in two-dimensional nozzles with various widths. Sabathil et al. [7] investigated the use of efficient application of 
optical measurement to reduce PM. Köpple et al. [8] investigated the parameters affecting spray-wall interaction in a GDI engine for the prediction of PM by numerical simulation.

A typical example of the fuel spray in a side-injection engine is illustrated in Figure 1. Complex air flows are generated around the tip of a fuel injector, so the effect of the air flows around the tip on fuel film formation needs to be investigated. Computational fluid dynamics (CFD) is an effective tool to study the complex phenomena of the fuel film on the tip of the injector. The fuel film adhering to the wall and the breakup of fuel plumes injected by the nozzles have mainly been simulated by using interface capturing methods such as the volume-of-fluid (VOF) (Hirt and Nichols [9]) and level-set (Sussman, et al. [10], Tanguy and Berlemont [11], Pan and Suga [12]) methods; the surface tension at the gas-liquid interfaces and wettability (ex. contact angle) at the gas-liquid-solid interfaces on the wall are considered. In fuel film simulations, the fuel film on the wall is typically much thinner than the film spread, so many computational meshes are required to minimize numerical diffusion of the gas-liquid interfaces. Particle methods such as the moving particle semi-implicit (MPS) (Koshizuka and Oka [13]) and smoothed particle hydrodynamics (Gingold and Monaghan [14]) methods are suitable for liquid adhesion simulation because the numerical diffusion of the gas-liquid interfaces is smaller than with the interface capturing methods due to simulating the particle motions with a Lagrange equation.

In this study, we investigated the spread of fuel film adhering to the tip of a fuel injector for GDI engines. First, we clarified the relationship between fuel adhesion and carbon deposits on the wall by comparing simulation results with experimental ones. The spread of fuel film adhering to the tip of the injector was simulated using the MPS method. Furthermore, we utilized a CFD approach based on our previously developed particle/grid hybrid method (Ishii, et al. [15-17]) to study the effect of the surrounding air flow generated by the spray plumes on fuel film behaviors. The spread of the fuel film on the wall and the spray plumes from the nozzles were simulated using Koshizuka et al.'s MPS method, and the air flow around the tip was simulated using an interface capturing method (Yabe and Aoki's [18] cubic interpolated propagation (CIP) method).

\section{(a)}

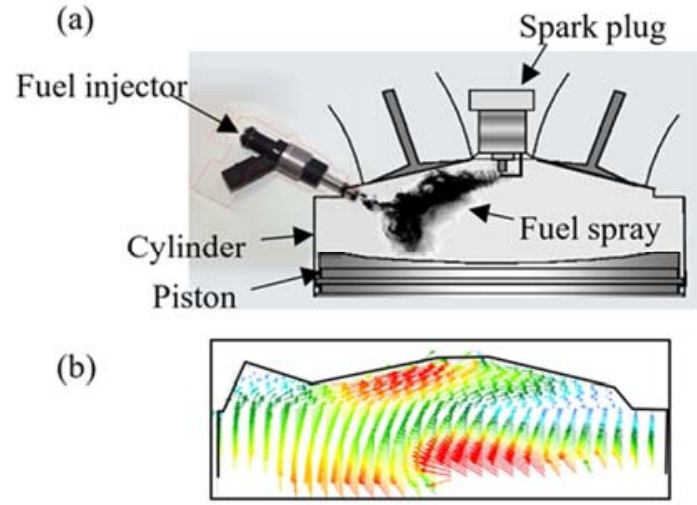

Figure 1. Schematic of GDI engine: (a) fuel spray with side injection and (b) air flow in cylinder.

\section{Simulation Model}

The simulation model (Figure 2) we used is the hybrid one we previously used (Ishii et al. [15-17]). It integrates Yabe and Aoki's CIP method [18] with Koshizuka and Oka's MPS method [13]. Fuel flow in the flow paths of the fuel injector and air flows in the air region were simulated using the CIP method. Fuel adhesion on the tip of the fuel injector and the spray plumes from the nozzles were simulated using the MPS method. The equations governing fuel flow and air flow are, respectively,

$$
\begin{gathered}
\frac{\partial f}{\partial t}+u_{j} f_{, j}=g \\
f=\left[\begin{array}{c}
F \\
\rho \\
u_{i} \\
p
\end{array}\right] g=\left[\begin{array}{c}
0 \\
-\rho u_{j, j} \\
-\frac{1}{\rho} p_{, j}+\frac{1}{\rho} \tau_{i j, j}+\frac{1}{\rho} S_{j} \\
-\rho C_{s}^{2} u_{j, j}
\end{array}\right],
\end{gathered}
$$

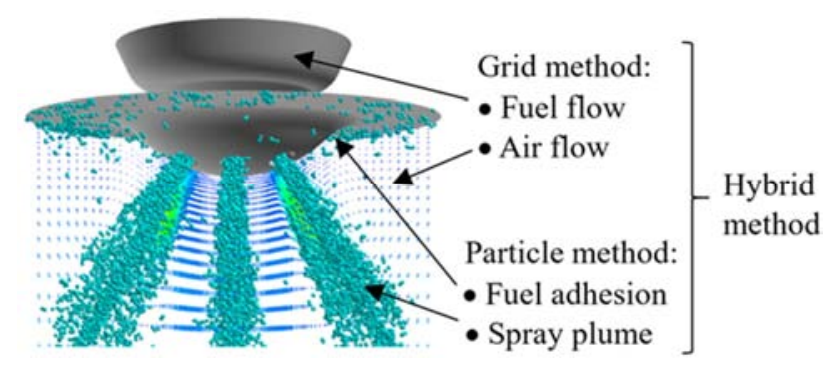

Figure 2. Simulation model of spray plumes around nozzles.

where $u$ is velocity, $\rho$ is density, $p$ is pressure, $t_{i j}$ is shear stress, $S_{j}$ is volume force, and $C_{s}$ is the speed of sound. While these equations are non-conservative forms of the convection terms, Yabe and Aoki [18] confirmed that they yield good conservation. The equations governing fuel adhesion on the wall of the fuel injector tip and the spray plume from the nozzle are,

$$
\begin{gathered}
\frac{\partial \rho}{\partial t}=0 \\
\rho \frac{D \vec{u}}{\partial t}=-\nabla p+\mu \nabla^{2} \vec{u}+\vec{F}_{v}
\end{gathered}
$$

where operator $D$ indicates Lagrangian differentiation, and $F_{v}$ is the volume force (including surface tension). We used the surface tension model developed in our previous work (Ishii, et al. [19, 20]). No turbulence model was used in the simulation because there are few such models that can be used with the particle method.

The hybrid method comprises two steps, as shown in Figure 3. In step 1, the advection equations are solved using the MPS and CIP methods. The advection velocities in both methods are modified using a weight function of the distance from the gas-liquid interface given by CIP and the particle density given by MPS. In step 2, the non-advection equations are solved using the MPS and CIP methods: the diffusion and source, pressure and velocity (and positions of particles in MPS method) are solved. Upon completion of step 2, the 
next iteration begins by returning to step 1 .

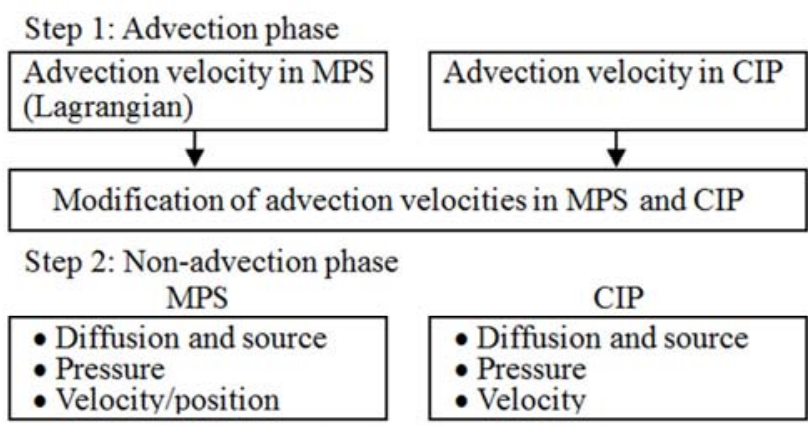

Return to step 1 for the next iteration

Figure 3. Steps in hybrid method.

To simulate droplet adhesion and spreading on the wall of the fuel injector tip, we applied a surface tension model with inter-particle force (Ishii, et al. [19, 20]) to the particle simulation using the MPS method. The roughness of the wall surfaces due to the deposits was simply considered by using the Wenzel and Cassie-Baxter models (Wang, et. al. [21]). Figure 4 (a) shows the change in droplet height due to surface roughness. The simulated changes in droplet height are also plotted, where the ratio of the actual surface to the geometrical surface was set to 2.0 in the Wenzel model, and the ratio of the solid-liquid interface area to the unity interface area was set to 0.12 in the Cassie-Baxter model. Figures 4 (b), (c) and (d) show simulated droplets with contact angles of 60, 90 and 150 degrees. The initial droplet shape was set as hemispheric, and the initial droplet diameter was set to $37.5 \mathrm{~mm}$. Density and surface tension were set to $798 \mathrm{~kg} / \mathrm{m}^{3}$ and $23.61 \times 10^{-3} \mathrm{~N} / \mathrm{m}$ respectively.

(a)

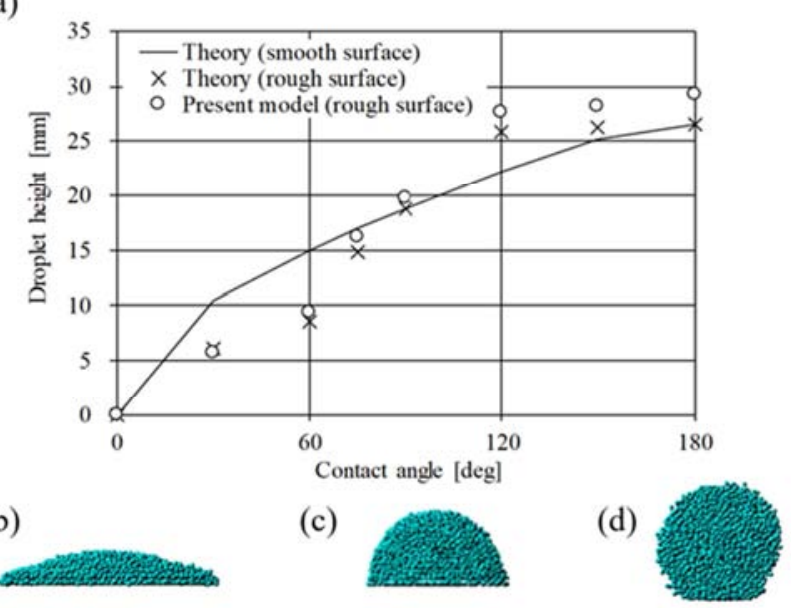

Figure 4. Change in droplet height due to surface roughness, and simulated droplets with contact angles of (b) 60 degrees, (c) 90 degrees and (d) 150 degrees.

\section{Experimental Setup}

The specifications of the experimental setup for measuring the spray plumes around the nozzles of a fuel injector tip are provided in Table 1. Fuel was pressurized using a tank of $\mathrm{N}_{2}$ gas and then injected from the fuel injector into a chamber. Images of the fuel spray were taken using a long-distance microscope with a charge coupled device (CCD) camera synchronized with a YAG laser pulse. The flash duration was set to $10 \mathrm{~ns}$. A personal computer was used to send the trigger pulse to the camera (RedLake MegaPlus 2 ES 2020). The side of the chamber was $48 \mathrm{~cm}$, the height was $56 \mathrm{~cm}$, and the depth was $42 \mathrm{~cm}$.

Table 1. Specifications of experimental setup for measuring spray plumes around nozzles.

\begin{tabular}{ll}
\hline Equipment & Specification \\
\hline Camera & RedLake MegaPlus 2 ES 2020 \\
Light & Nd: YAG laser \\
& Flash duration: $10 \mathrm{~ns}$ \\
& Side: $48.0 \mathrm{~cm}$ \\
Chamber & Height: $56 \mathrm{~cm}$ \\
& Depth: $42 \mathrm{~cm}$ \\
& Window diameter: $15 \mathrm{~cm}$ \\
\hline
\end{tabular}

\section{Results and Discussion}

First, we discuss the relationship between fuel adhesion and the carbon deposits that formed on the nozzle tip by comparing the experiment and simulation results. Droplet adhesion on the tip was simulated using the MPS method. Figure 5 shows the initial condition of the simulation: 101 cube droplets with $180-\mu \mathrm{m}$ sides adhered to the wall. The arrow indicates the direction of the volume force given by air flow. Air resistance on the droplets (Reitz, R. D. [22]) was taken simply as the volume force in order to shorten the computation time. Acceleration force on the particles was calculated using

$$
\begin{gathered}
\frac{d \vec{u}_{d}}{d t}=\frac{3 \rho_{a}}{4 \rho_{d} d_{d}} C_{D}\left|\vec{u}_{a}-\vec{u}_{d}\right|\left(\vec{u}_{a}-\vec{u}_{d}\right), \\
C_{D}=\left(0.63+4.8 / \sqrt{R e_{d}}\right)^{2}, \\
R e_{d}=\left|\vec{u}_{a}-\vec{u}_{d}\right| d_{d} \rho_{a} / \mu_{a},
\end{gathered}
$$

where $u$ is droplet velocity, $\rho$ is density, $d$ is droplet diameter, and $\mu$ is viscosity. Subscripts $a$ and $d$ refer to air and droplet. Initial droplet velocity was set to zero, as the droplet velocity was much lower than the air velocity. The air velocity around the tip of a fuel injector is typically about $10.0 \mathrm{~m} / \mathrm{s}$. Three air velocities-3.1 m/s, $11.5 \mathrm{~m} / \mathrm{s}$, and $40.1 \mathrm{~m} / \mathrm{s}$-were used. Table 2 lists the specifications of the fuel and air. Fuel surface tension was set to $20.14 \times 10^{-3} \mathrm{~N} / \mathrm{m}$, and the Young contact angle was 10 . Table 3 shows the specifications of the fuel injector. The injector tip had the shape of a hill sloping downward, so there were both concave and convex wall surfaces. Six nozzles, each with a diameter of $250 \mu \mathrm{m}$, were placed on the tip, and the diameter of the circle for nozzle positioning was $1.0 \mathrm{~mm}$. The roughness on the wall surfaces was simplified using the Wenzel and Cassie-Baxter models: the ratio of the actual surface to the geometrical surface was set to 2.0 in the Wenzel model, and the ratio of the solid-liquid interface area to the unity interface area was 
set to 0.12 in the Cassie-Baxter model. The computation times were about 30 minutes on a personal computer with a $3.00 \mathrm{GHz}$ CPU.

Table 2. Specifications of fuel and air.

\begin{tabular}{lll}
\hline & Fuel & Air \\
\hline Temperature & $298 \mathrm{~K}$ & \\
Viscosity & $4.17 \times 10^{-4} \mathrm{~Pa} \cdot \mathrm{s}$ & $1.83 \times 10^{-5} \mathrm{~Pa} \cdot \mathrm{s}$ \\
Density & $684 \mathrm{~kg} / \mathrm{m}^{3}$ & $1.20 \mathrm{~kg} / \mathrm{m}^{3}$ \\
Surface tension & $20.14 \times 10^{-3} \mathrm{~N} / \mathrm{m}$ & - \\
Ambient pressure & - & $0.1 \mathrm{MPa}$ \\
Injection pressure & $10.1 \mathrm{MPa}$ & - \\
\hline
\end{tabular}

Table 3. Specifications of fuel injector.

\begin{tabular}{ll}
\hline & Specification \\
\hline Number of nozzles & RedLake MegaPlus 2 ES 2020 \\
& Nd: YAG laser \\
Diameter of nozzle & Flash duration: $10 \mathrm{~ns}$ \\
& Side: $48.0 \mathrm{~cm}$ \\
Diameter of circle for & Height: $56 \mathrm{~cm}$ \\
nozzle positioning & Depth: $42 \mathrm{~cm}$ \\
& Window diameter: $15 \mathrm{~cm}$ \\
Injection frequency & $2.0 \mathrm{~Hz}$ \\
Pulse duration & $1.0 \mathrm{~ms}$ \\
\hline
\end{tabular}

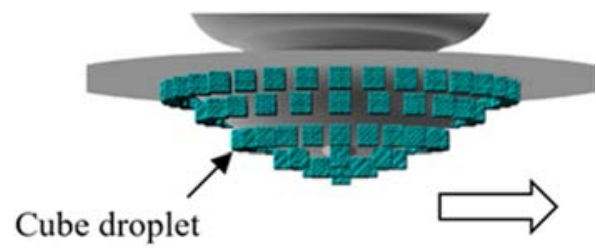

Volume force

Figure 5. Initial condition of droplet adhesion simulation: 101 cube droplets with 180- $\mu$ m sides placed on a wall.

Figure 6 shows a comparison of (a) the experimental carbon deposit distribution with (b) the simulated droplet adhesion distribution. In the experiment, the carbon deposits and the droplet adhesions were unevenly distributed in the air flow direction. The air flow was from left to right, so carbon deposits mainly formed on the right side. Furthermore, they were formed around the outer edge and at the center of the hill shape of the tip, and patchy adhesions formed on the outer ring of the hill shape. The simulated droplet adhesion distribution qualitatively agreed with the measured carbon deposit distribution. Specifically, fuel adhesion formed on the concave and convex wall surfaces; the fuel adhesion on the wall surface of the nozzle tip were also formed around the outer edge and at the center of the hill. This is because when the fuel film is formed, the place where the contact angles of the entire circumference of a film tip become uniform to keep balance of surface tension forces, corresponds to these places of the outer edge and the center of the hill.

Figure 7 shows the dependency of the droplet adhesion on the tip of the fuel injector on the air velocity. As mentioned, the air velocity was set to (a) $3.1 \mathrm{~m} / \mathrm{s}$, (b) $11.5 \mathrm{~m} / \mathrm{s}$, and (c) $40.1 \mathrm{~m} / \mathrm{s}$. With the lowest air velocity $(3.1 \mathrm{~m} / \mathrm{s})$, the droplet adhesions were evenly distributed on the concave and convex wall surfaces. In contrast, with the highest air velocity (40.1 $\mathrm{m} / \mathrm{s}$ ), the droplet adhesions formed unevenly in the air flow direction, and the size of the patchy adhesion area was smaller than when the air velocity was $11.5 \mathrm{~m} / \mathrm{s}$. The results shown in Figure 7 demonstrates that the shape of the fuel injector tip and the air flow around the tip both affect the droplet adhesion distribution. We conclude that optimization of the hill shape of the tip, particularly the concave portion, is important for reducing carbon deposits. Deposit (surface roughness) formed on the wall of the nozzle tip changes over time. Therefore, the contact angle of the fuel film adhering to the wall surface is also changed, wetting spread phenomenon of the fuel film is also affected (Wang, at al. [21]). Threfore, strictly, it is necessary to consider the dynamic contact angle when considering the wetting spread of the fuel film. Changes of contact angle over time and the effects of the dynamic contact angle are need to be studied in future works.

Next, we discuss the behaviors of the droplets floating in the air region between fuel injections by comparing experimental results with simulation ones. Figure 8 shows droplets floating in the air region around the nozzles between injections. The times shown in the figure are times relative to a reference time (the time when the spray plumes reached a steady state). After the injector valve started to close, the atomized spray plumes changed into fuel column breakups with large droplets between $0.3 \mathrm{~ms}$ and $0.4 \mathrm{~ms}$, and several large droplets remained in the air region at $0.5 \mathrm{~ms}$.

Figure 9 shows the fuel film behaviors on the tip of the fuel injector. The times shown in the figure are relative times from a reference time when spray plumes became a steady state. The dashed lines indicate the leading edge of the fuel film. It moved from top to bottom toward the nozzles: specifically, the leading edge was located at the top of the picture at $0.0 \mathrm{~m}$, part of it came into contact with the outer edge of a nozzle at $0.1 \mathrm{~ms}$, and part of the fuel film was sucked into the nozzle between 0.2 and $0.3 \mathrm{~ms}$.

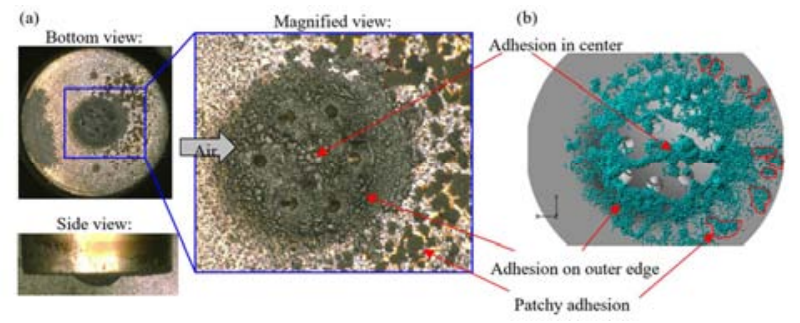

Figure 6. Comparison of (a) measured carbon deposit distribution with (b) simulated droplet adhesion distribution.

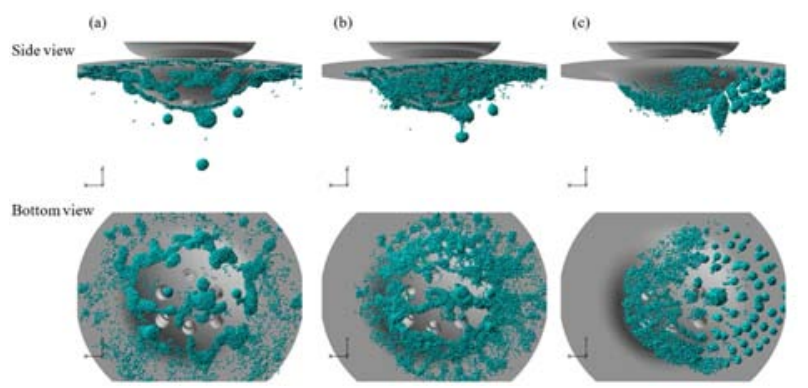

Figure 7. Dependency of air velocity on distribution of droplet adhesion. Air velocity was (a) $3.1 \mathrm{~m} / \mathrm{s}$, (b) $11.5 \mathrm{~m} / \mathrm{s}$, and (c) $40.1 \mathrm{~m} / \mathrm{s}$. 

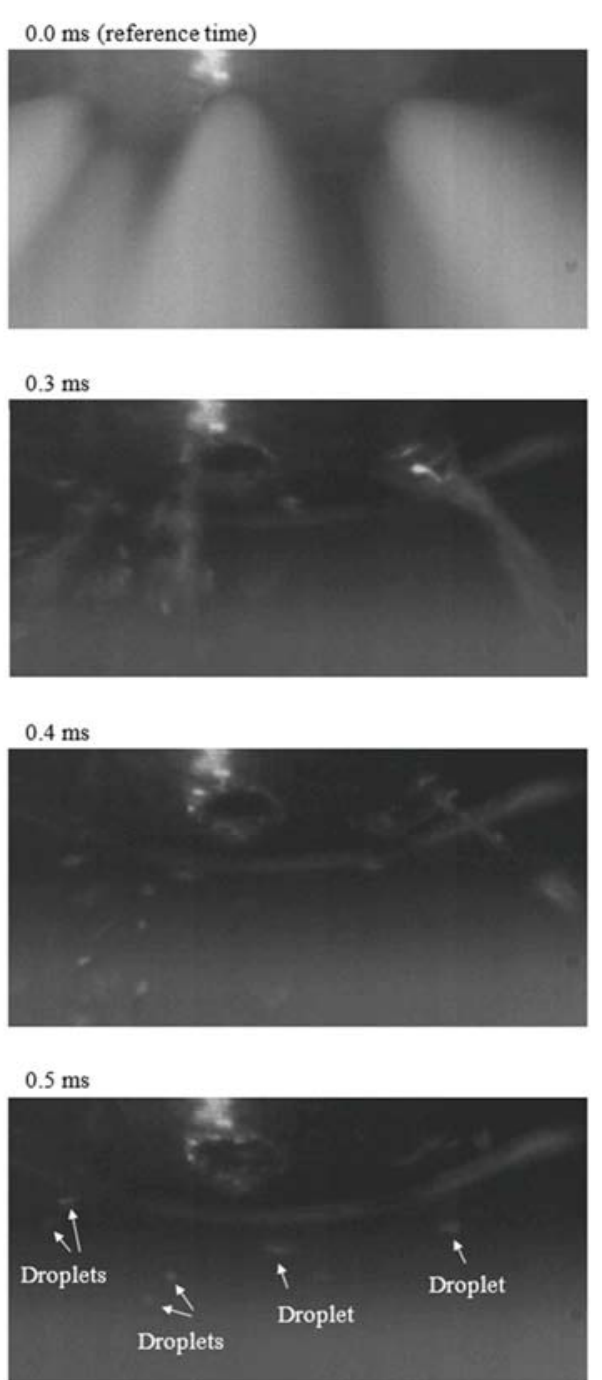

Figure 8. Droplets floating in air region around nozzles. Large droplets remained in air region at $0.5 \mathrm{~ms}$ after fuel injection.

To investigate the behaviors of the droplets floating in the air region between fuel injections and the spread of the fuel film on the tip of the fuel injector, we ran a fuel spray simulation with fuel droplet adhesions on the tip wall. Table 2 shows the specifications of fuel and air, and Table 3 shows those of the fuel injector. The initial droplet adhesion distribution on the tip was determined using the simulation procedure in Figure 6, after which we simulated the adhesion of the floating droplets to the wall and the spreading of the fuel film to the nozzles. Figure 10 shows the simulated adhesion of droplets floating in the air region around the tip of the fuel injector, along with the fuel film spread on the wall of the tip. In experiments with real fuel injectors, there is a time delay of about $0.3 \mathrm{~ms}$ from zero to completion of a valve stroke.

In this study, we started the simulation with a full stroke of the valve in order to shorten the computation time, so the spray plumes reached a steady state sooner than in the experiments. The times shown in Figure 10 were normalized by the characteristic time:

$$
t^{*}=\rho D / \sqrt{2\left(p_{f}-p_{b}\right)},
$$

where $\rho$ is fuel density (same as fuel droplet density, $\rho_{d}$ ), $D$ is a nozzle diameter of $250 \mu \mathrm{m}, p_{f}$ is fuel pressure created by a fuel pump, and $p_{b}$ is the back pressure in the air region. At the start of the computation $\left(t^{*}=0.0\right)$, floating droplets were placed in the air region around the tip of the fuel injector, and fuel films were placed on the wall. At $t^{*}=6.8$, spray plumes started to be ejected from the nozzles, and floating droplets were pulled toward the wall of the injector tip. The fuel films that formed on the wall started to spread over a wide area. At $t^{*}=13.7$, fuel columns formed under the nozzles, and the floating droplets were pulled toward the wall of the injector tip; several droplets hit the wall and spread over it in the form of fuel film.

At $t^{*}=18.8$, the fuel films spread toward the nozzles, and several of them came into contact with the ejected spray plumes at the nozzle outlets. At $t^{*}=23.9$, parts of the fuel films were sucked into the spray plumes and re-injected into the air region. The computation times were about five hours on a personal computer with a $3.00 \mathrm{GHz} \mathrm{CPU}$.
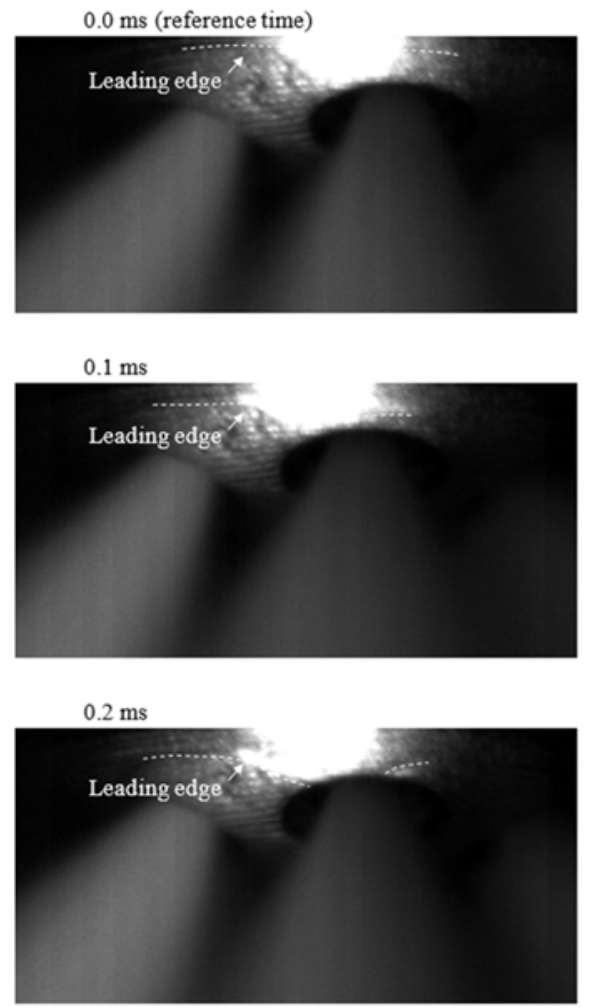

$0.3 \mathrm{~ms}$

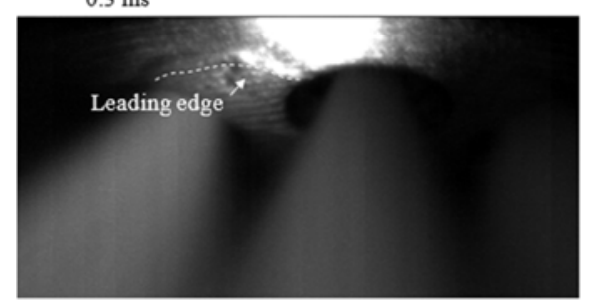

Figure 9. Fuel film spreading toward nozzles. Fuel film on wall spread toward nozzles during fuel injection. 


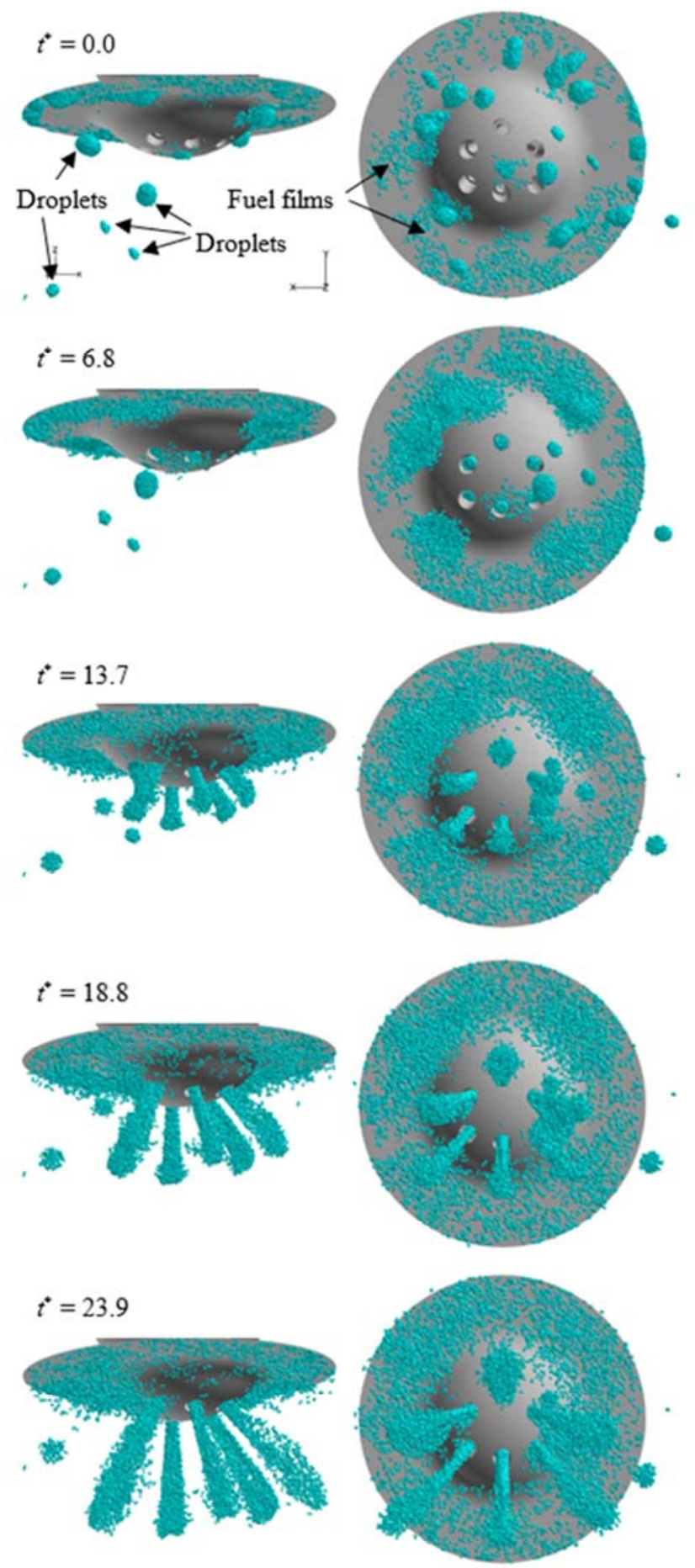

Figure 10. Simulated adhesion of droplets floating in air region and fuel film spreading toward nozzles.

Figure 11 shows the velocity distribution in the air region around the nozzles at two times: $t^{*}$ of 13.7 , when the spray plumes were growing, and $t^{*}$ of 59.8 , when the spray plumes were in a steady state. As the velocity directions in the figure show, the vectors of the air flows that moved toward the wall of the fuel injector tip increased as the spray plumes grew. Furthermore, the air flow around the wall of the nozzle outlets moved toward the nozzles along the wall of the injector tip.

We found that the floating droplets were pulled toward the wall due to the air flow directed at the wall and that the fuel films spread toward the injection nozzles due to an air flow along the wall toward the injection nozzles. Parts of the fuel films were sucked into the spray plumes and then re-injected into the air region. The simulated fuel film behaviors on the wall qualitatively agreed with the measured ones. These results demonstrate that optimizing the surface shape of the fuel injector tip is important for reducing nozzle tip fuel wetting in order to reduce particulate matter. There are several factors in the generation of the fule adhesion. In addition to the fuel adhering to the nozzle tip by the reverse air flow shown in Figure 11, fuel films that are exposed to the nozzle tip by collisions of the spray plumes with the inner-wall surfaces at the nozzle outlets are also need to be reduced (Huang et al. [1]). In order to reduce PM, it is necessary to reduce the amount of fuel film on the nozzle tip. An examination of the effects of these other causes will be the focus of future work.
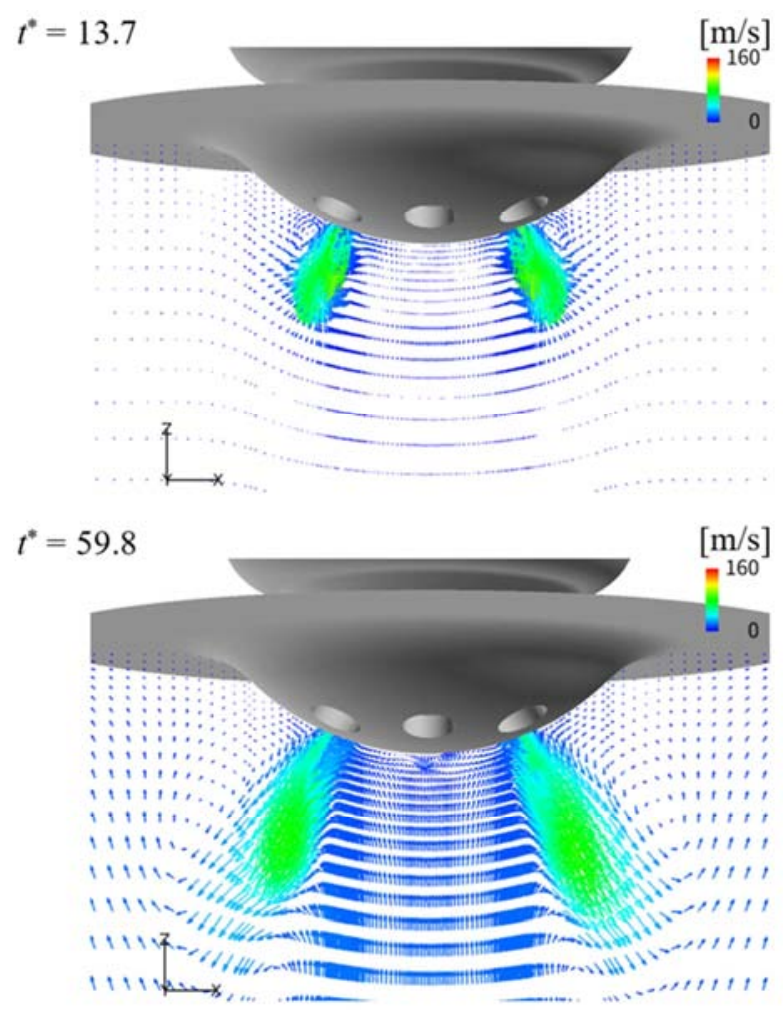

Figure 11. Velocity distribution in air region around nozzles.

\section{Conclusion}

We simulated the spread of fuel adhering to the tip of a fuel injector for GDI engine.

1. The spread of fuel adhering to the tip of a fuel injector was simulated using the moving particle semi-implicit method, and a previously developed particle/grid hybrid method was used to study the effects of spray plumes.

2. In the experiment, air flow was from left to right, so the carbon deposits mainly formed on the right. The deposits formed around the outer edge and around the center of 
the hill shape of the tip, and patchy adhesions formed on the outer ring of the hill shape. The simulated droplet adhesion distribution qualitatively agreed with the measured carbon deposit distribution.

3. The behavior of the floating droplets in the air region between fuel injections was investigated by comparing the experimental results with the simulation ones. The floating droplets were pulled toward the wall of the injector tip, and some of them hit the wall and spread over it in the form of fuel film. The fuel films spread toward the nozzles due to the air flow generated by the spray plumes, and several fuel films came into contact with the spray plumes ejected at the nozzle outlets. Parts of the fuel films were sucked into the spray plumes and re-injected into the air region. We found that optimization of the hill shape of the tip, especially regarding the concave portion, is important for reducing carbon deposits.

\section{References}

[1] Huang, W., Moon, S., Wang, J., Murayama, K., Arima, T., Sasaki, Y., and Arioka, A. (2019). Nozzle Tip Wetting in Gasoline Direct Injection Injector and Its Link with Nozzle Internal Flow. Int. J. Engine Res., 21 (2), 340-351.

[2] Khan, M. M., Hélie, J., Gorokhovski, M, and Sheikh, N. A., (2017). Experimental and Numerical Study of Flash Boiling in Gasoline Direct Injection Sprays. Appl. Therm. Eng., 123, 377-389.

[3] Senda, J., Hojyo, Y., and Fujimoto, H., (1994). Modeling of Atomization Process in Flash Boiling Spray, International Fuels \& Lubricants Meeting \& Exposition. SAE Transactions, 103 (4), 1026-1040.

[4] Araneo, L. and Dondé, R., Flash Boiling in a Multihole G-DI Injector - Effects of the Fuel Distillation Curve. Fuel, 2017, $191(1), 500-510$.

[5] Nouri, J. M., Mitroglou, N., Yan, Y., and Arcoumanis, C. (2007). Internal Flow and Cavitation in a Multi-Hole Injector for Gasoline Direct-Injection Engines. SAE Technical Paper No. 2007-01-1405.

[6] Sou, A., Prasetya, R., Moon, S., Wada, Y., and Yokohata, H. (2016). Synchrotron X-Ray Phase Contrast Imaging of Cavitation in Fuel Injector Nozzles with Various Sizes, 9th International Conference on Multiphase Flow. Proc. of ICMF-2016, May 22-27, Firenze, Italy.

[7] Sabathil, D., Schaffner, P., and Königstein, A. (2012). Efficient Application of Optical Measurements to Reduce the Particle Emission from Direct-Injection Gasoline Engines. $10^{\text {th }}$ International Symposium on Combustion Diagnostics, May 22-23, Baden-Baden, Germany.

[8] Köpple, F., Jochmann, P., Kufferath, A. H., and Bargende, M. (2013). Investigation of the Parameters Influencing the
Spray-Wall Interaction in a GDI Engine - Prerequisite for the Prediction of Particulate Emissions by Numerical Simulation. SAE Int. J. Engines, 6 (2), 911-925.

[9] Hirt, C. W. and Nichols, B. D. (1981). Volume of Fluid (VOF) Method for the Dynamics of Free Boundaries. J. Comput. Phys., 39 (1), 201-225.

[10] Sussman, M. Smereka, P., and Osher, S. (1994). A Level Set Approach for Computing Solutions to Incompressible Two-Phase Flow. J. Comput. Phys., 114 (1), 146-159.

[11] Tanguy, S. and Berlemont, A. (2005). Application of a Level Set Method for Simulation of Droplet Collisions. Int. J. Multiph. Flow, 31 (9), pp. 1015-1035.

[12] Pan, Y. and Suga, K. (2004). Direct Simulation of Water Jet into Air. Proc. of 5th Int. Conf. on Multipase Flow, Yokohama, Japan, May 30-June 4, Paper No. 377.

[13] Koshizuka, S. and Oka, Y. (1996). Moving-Particle Semi-Implicit Method for Fragmentation of Incompressible Fluid. Nucl. Sci. Eng., 123 (3), 421-434.

[14] Gingold, R. A. and Monaghan, J. J. (1982). Kernel Estimates as a Basis for General Particle Methods in Hydrodynamics. J. Comput. Phys., 46 (3), 429-453.

[15] Ishii, E., Ishikawa, T., and Tanabe, Y. (2006). Hybrid Particle/Grid Method for Predicting Motion of Micro- and Macro-Free Surfaces. ASME J. Fluids Eng., 128 (5), 921-930.

[16] Ishii, E., Ishikawa, M., Sukegawa, Y., and Yamada, H. (2011) Secondary-Drop-Breakup Simulation Integrated with Fuel-Breakup Simulation near Injector Outlet. ASME J. Fluids Eng., 133 (8), 081302-1 - 081302-8.

[17] Ishii, E., Yoshimura, K., Yasukawa, Y., and Ehara, H. (2016) Late-Fuel Simulation near Nozzle Outlet of Fuel Injector During Closing Valve. ASME J. Eng. Gas Turbines Power, 138 (10), 102801-1 - 102801-9.

[18] Yabe, T. and Aoki, T. (1996). A Dream to Solve Dynamics of All Materials Together. Proc. of International Conference on High-Performance Computing in Automotive Design, Engineering, and Manufacturing, Oct. 7-10, Paris, France, 2105-2108.

[19] Ishii, E. and Sugii, T. (2012). Surface Tension Model for Particle Method using Inter-Particle Force Derived from Potential Energy. ASME Paper No. FEDSM2012-72030, 569-578.

[20] Ishii, E. and Sugii, T. (2012). Spreading-Droplet Simulation With Surface Tension Model Using Inter-Particle Force in Particle Method. ASME Paper No. IMECE2013-62542.

[21] Wang, J., Wu, Y., Cao, Y., Li, G., and Liao, Y. (2020). Influence of Surface Roughness on Contact Angle Hysteris and Spreading Work. Colloid and Polymer Science, 298, 1107-1112.

[22] Reitz, R. D. (1987). Modeling Atomization Processes in High Pressure Vaporizing Sprays. At. Spray Technol., 3 (4), 309-337. 